\title{
Original
}

\section{Effects of Gentle Cutaneous Stimulation Using Contact and Sham Acupuncture on the H/M Ratio in Patients with Chronic Hemiparesis}

\author{
Miyuki Matsumoto ${ }^{* 1)}$, Masazumi Mrzuma ${ }^{1)}$, Nobuyuki Kawate ${ }^{1)}$, \\ Shinsuke $\mathrm{SATOH}^{2)}$, Masato $\mathrm{NagAO}^{3)}$ and Ari YuAsa ${ }^{4)}$
}

\begin{abstract}
This study aimed to evaluate the neurophysiological effects of gentle cutaneous stimulation by acupuncture on muscle tone in patients with chronic spastic paresis. We conducted a randomized, double-blind, crossover trial comparing the effects of contact acupuncture on the $\mathrm{H} / \mathrm{M}$ ratios of soleus muscles between 8 patients with spastic paresis and 17 healthy volunteers. The study subjects were randomly assigned to two groups, and then they received gentle stimulations to their lower limb (affected side) using skin attachment-type contact acupuncture and sham acupuncture in different order. Fourteen acupuncture points were selected according to the Meridian-Test (M-Test). The soleus muscle in both stimulated and unstimulated limbs was analyzed by electromyography following tibial electrical stimulation at the popliteal fossa, and the $\mathrm{H} / \mathrm{M}$ ratios were then calculated. Paretic subjects showed a significant decrease in $\mathrm{H} / \mathrm{M}$ ratio after both contact and sham acupunctures in the stimulated limbs, but not in the unstimulated limbs (unaffected side), and this result was not affected by the order of stimulation. Healthy subjects showed a significant decrease in the $\mathrm{H} / \mathrm{M}$ ratio after both contact and sham acupunctures in both stimulated and unstimulated limbs. The H/M ratio decrease indicates a decreased overall percentage of activated $\alpha$-motor neurons. Our results therefore suggest that gentle cutaneous stimulation could reduce $\alpha$-motor neuron excitability at rest under some conditions.
\end{abstract}

Key words : muscle tone, chronic hemiparesis, H/M ratio, contact acupuncture, Meridian-Test (M-Test)

\section{Introduction}

Spasticity is a common symptom of upper motor neuron dysfunction due to abnormal muscle activity that impedes smooth movement. Rehabilitation with reduced muscle tone is thus crucial to achieve functional improvement in patients with spastic hemiparesis ${ }^{1)}$. Currently, electrical stimulation, ultrasound therapy, and muscle stretching are used alone or in combination to control muscle tone ${ }^{2,3)}$. Increased muscle tone is caused by excessive excitability of the muscle

1) Department of Rehabilitation Medicine, Showa University School of Medicine, 1-5-8 Hatanodai, Shinagawa-ku, Tokyo 142-8666, Japan.

2) Nishi-Hiroshima Rehabilitation Hospital.

3) Department of Orthopaedic Surgery, University of California.

4) Graduate School of Comprehensive Human Sciences, University of Tsukuba.

* To whom corresponding should be addressed. 
stretch reflex, and is characterized by increased excitatory input and decreased inhibitory input to $\alpha$-motor neurons. The $\mathrm{H} / \mathrm{M}$ ratio is considered an index of stretch reflex excitability and has been widely used for quantitatively evaluating muscle tone ${ }^{4-9)}$.

Numerous studies have examined the effects of acupuncture stimulation on increased muscle tone in stroke patients ${ }^{10-11)}$. Many prior studies employed either electrical or manual acupuncture stimulation, and to the best of our knowledge, none similarly examined the effects of skin attachment-type (with tape) contact acupuncture (hereafter referred to as contact acupuncture). We therefore conducted a randomized, double-blind, crossover trial to examine the neurological effects of cutaneous stimulation with contact acupuncture on muscle tone in chronic stroke patients with spastic paresis by measuring the $\mathrm{H} / \mathrm{M}$ ratios of their soleus muscles. The control subjects were recruited from among healthy volunteers without central nervous system diseases since the H-reflex is influenced by both the central and the peripheral nervous system. Measurements were performed on both lower limbs to compare the effects of prolonged rest and contralateral effects on the unaffected limbs.

\section{Methods}

\section{Subjects}

Table 1 shows the physical characteristics of our subjects. The paretic subjects consisted of 8 stroke patients with chronic hemiparesis [6 males and 2 females with a mean age of 56.9 years (36-74 years) and a mean post-onset time of 10 years and 3 months (47-286 months)] from the Showa University Fujigaoka Rehabilitation Hospital. Inclusion criteria were as follows : elapse of at least 2 years since the onset, confirmed hypertonia of the plantar flexor muscles with a score of 1-3 on the Modified Ashworth Scale (MAS) ${ }^{12)}$, and the lower limb Brunnstrom recovery stage was at least III $^{13-14)}$. The control group consisted of 17 healthy volunteers [10 males and 7 females with a mean age of 45.2 years (22-73 years)] from the basic resident of Kanagawa or Tokyo. Exclusion criteria were age 15 years or younger and any communication impairment.

\section{Experimental set up}

1) Study design

Fig. 1 shows the study design. We fully explained the study procedures to all subjects, and then allowed them at least one week to decide whether or not to participate in this study. After informed consent had been obtained, the subjects were randomly assigned to two groups (groups $\mathrm{A}$ and $\mathrm{B}$ ). Prior to undergoing the measurements, the subjects were instructed to rest in a prone position for five minutes and electrodes were affixed to the lower limbs. The electrode positions remained unchanged until completion of the measurement procedures. Each measurement was performed 5 times per session and the mean $\mathrm{H} / \mathrm{M}$ ratio was calculated to reduce variability effects among measurements. For group A, we first measured the prestimulation $\mathrm{H} / \mathrm{M}$ ratio (1) of the stimulated limb (affected side). Immediately thereafter the contact acupuncture was applied, and the subjects were instructed to rest for at least 15 minutes (but not more than 30 minutes) considering the slow adaptation of mechanoreceptors in the 
Table 1. Physical characteristics of paretic and healthy volunteers

\begin{tabular}{|c|c|c|c|c|c|c|c|c|}
\hline Pt. & $\begin{array}{c}\text { Age } \\
\text { Gender }\end{array}$ & $\begin{array}{l}\text { Affected } \\
\text { side }\end{array}$ & Group & Diagnosis & $\begin{array}{c}\text { Duration } \\
\text { (years, } \\
\text { months) }\end{array}$ & $\begin{array}{l}\text { Modified } \\
\text { Ashworth } \\
\text { Scale }\end{array}$ & $\begin{array}{l}\text { Brunnstrom } \\
\text { stage }\end{array}$ & Ambulation aids \\
\hline A & $65 \mathrm{M}$ & Right & $\mathrm{B}$ & $\mathrm{SAH}$ & $19 \mathrm{y} 1 \mathrm{~m}$ & $1+$ & VI - VI - VI & \\
\hline B & $36 \mathrm{M}$ & Left & B & $\mathrm{CI}$ & $3 y 11 \mathrm{~m}$ & 3 & III - II - IV & $\begin{array}{l}\text { Ankle foot orthosis, } \\
\text { Cane, Wheelchair }\end{array}$ \\
\hline $\mathrm{C}$ & $41 \mathrm{~F}$ & Left & $\mathrm{B}$ & SAH & $23 \mathrm{y} 10 \mathrm{~m}$ & 2 & VI - VI - VI & \\
\hline $\mathrm{D}^{\dagger}$ & $74 \mathrm{M}$ & Right & $\mathrm{B}$ & $\mathrm{CI}$ & $6 y 7 \mathrm{~m}$ & 2 & IV - IV - IV & \\
\hline $\mathrm{E}$ & $72 \mathrm{M}$ & Right & A & Multiple $\mathrm{CH}$ & $4 y 5 \mathrm{~m}$ & 1 & VI - VI - VI & \\
\hline $\mathrm{F}$ & $60 \mathrm{M}$ & Left & A & SAH & $8 y 1 m$ & 3 & III - III - III & $\begin{array}{l}\text { Ankle foot orthosis, } \\
\text { Cane, Wheelchair }\end{array}$ \\
\hline G & $40 \mathrm{~F}$ & Right & A & $\mathrm{CH}$ & $7 \mathrm{y} 2 \mathrm{~m}$ & 2 & $V-V-I V$ & Ankle foot orthosis \\
\hline $\mathrm{H}$ & $67 \mathrm{M}$ & Left & A & $\mathrm{CH}$ & $8 \mathrm{y} 11 \mathrm{~m}$ & \multirow[t]{2}{*}{2} & VI - VI - V & $\begin{array}{l}\text { Ankle foot orthosis, } \\
\text { Cane }\end{array}$ \\
\hline & $\begin{array}{l}56.9^{*} \\
6 \mathrm{M} / 2 \mathrm{~F}\end{array}$ & $4 \mathrm{R} / 4 \mathrm{~L}$ & \multicolumn{2}{|l|}{$4 \mathrm{~A} / 4 \mathrm{~B}$} & $\begin{array}{c}10 \mathrm{y} 3 \mathrm{~m} \\
\pm 7 \mathrm{y} 3 \mathrm{~m}^{* *}\end{array}$ & & & \\
\hline \multicolumn{2}{|c|}{ Volunteers } & \multicolumn{2}{|c|}{ Age Gender } & Stimulated side & Group & \multicolumn{2}{|c|}{$\begin{array}{l}\text { Body mass } \\
\text { index }\end{array}$} & ry of present illness \\
\hline & 1 & \multicolumn{2}{|l|}{$45 \mathrm{~F}$} & Left & B & \multicolumn{2}{|c|}{20.6} & \\
\hline & 2 & \multicolumn{2}{|l|}{$40 \mathrm{M}$} & Right & $\mathrm{B}$ & \multicolumn{2}{|c|}{20.1} & \\
\hline & 3 & \multicolumn{2}{|l|}{$36 \mathrm{~F}$} & Right & A & \multicolumn{2}{|c|}{19.4} & \\
\hline & $4 \dagger$ & \multicolumn{2}{|l|}{$73 \mathrm{M}$} & Right & A & \multicolumn{2}{|c|}{25.3} & \\
\hline & 5 & \multicolumn{2}{|l|}{$40 \mathrm{M}$} & Left & A & \multicolumn{2}{|c|}{24.5} & \\
\hline & 6 & \multicolumn{2}{|l|}{$54 \mathrm{M}$} & Right & A & \multicolumn{2}{|c|}{18.5} & \\
\hline & 7 & \multicolumn{2}{|l|}{$66 \mathrm{~F}$} & Left & B & \multicolumn{2}{|c|}{23.2} & \\
\hline & 8 & \multicolumn{2}{|l|}{$27 \mathrm{~F}$} & Right & A & 20. & & \\
\hline & 9 & $54 \mathrm{~F}$ & & Right & B & 19. & & \\
\hline & 10 & $23 \mathrm{M}$ & & Left & A & 20. & & \\
\hline & 11 & $51 \mathrm{M}$ & & Right & A & 27. & & \\
\hline & 12 & $22 \mathrm{~F}$ & & Left & B & 20. & & \\
\hline & 13 & $38 \mathrm{M}$ & & Right & A & 29. & & Low back pain \\
\hline & 14 & $42 \mathrm{M}$ & & Right & B & 21. & & \\
\hline & 15 & $26 \mathrm{~F}$ & & Right & A & 20. & & \\
\hline & 16 & $70 \mathrm{M}$ & & Right & $\mathrm{B}$ & 19. & & \\
\hline & $17 \dagger$ & $63 \mathrm{M}$ & & Right & B & 22. & & \\
\hline & & $45.2 * 10 \mathrm{M}$ & & $12 \mathrm{R} / 5 \mathrm{~L}$ & $9 \mathrm{~A} / 8 \mathrm{~B}$ & & & \\
\hline
\end{tabular}

${ }^{*}$ : Mean, ${ }^{* *}$ : Mean \pm Standard Deviation, M : male, F : female, R : right, L : left, A : group A, B : group B, y : years, $\mathrm{m}$ : months, SAH : Subarachnoid hemorrhage, CI : Cerebral infarction, $\mathrm{CH}$ : Cerebral hemorrhage, $\dagger$ : dropout.

skin. Then, H/M ratio (2) was measured, followed by removal of the contact acupuncture and application of the sham acupuncture after a washout period of 15 minutes. The subjects were instructed to rest again as described above, and H/M ratio (3) was measured. For group B, the measurements were performed in a similar manner except that the sham acupuncture was performed first followed by the contact acupuncture. H/M ratio measurements of the unstimulated 


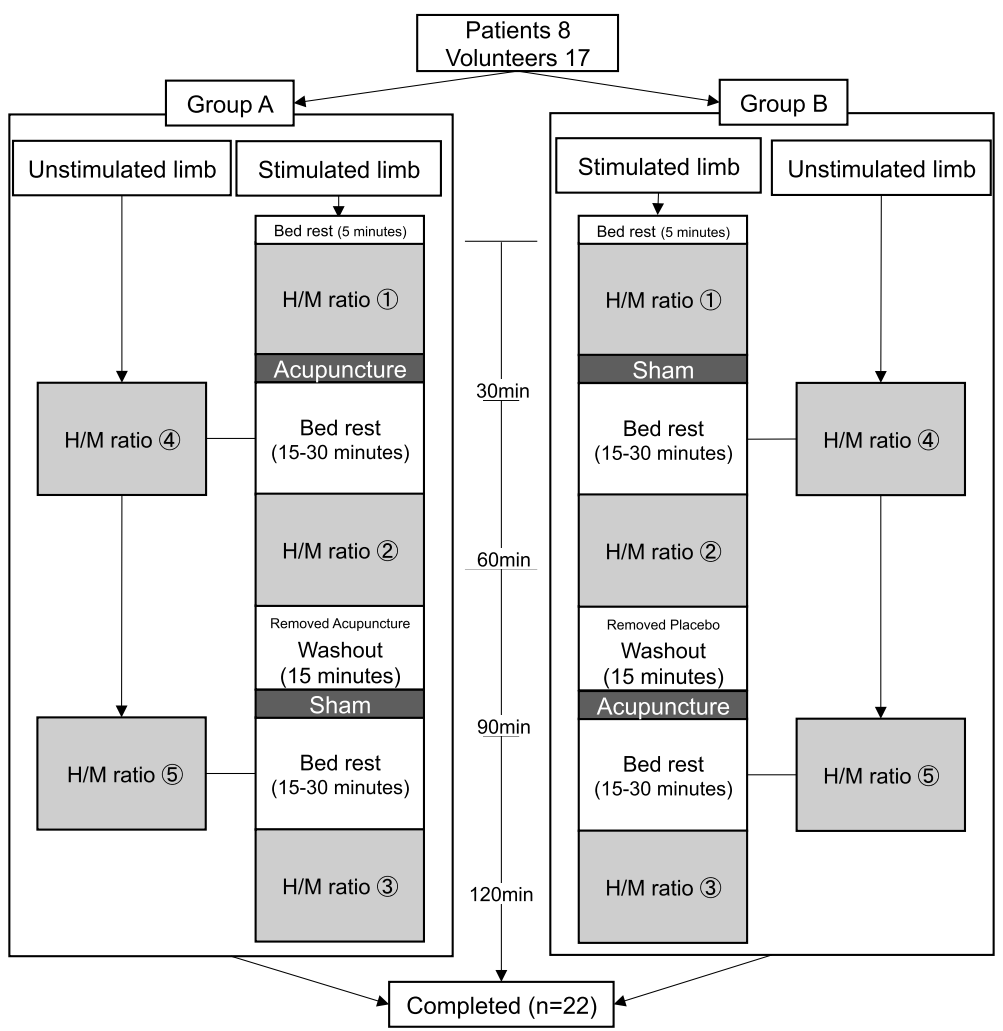

Fig. 1. Study design flow chart

limbs on the contralateral side (unaffected side) (4) were performed at the first bed rest time and (5) was performed at the second bed rest with an interval of at least 45 minutes from the measurements on the affected limb.

2) Measurement conditions of $\mathrm{H} / \mathrm{M}$ ratio and $\mathrm{H}$-reflex

The $\mathrm{H} / \mathrm{M}$ ratio was recorded for the soleus muscle using the Neuropac $\mu$ MEB-9100 ver. 08-06 (NIHON KOHDEN CO., Tokyo, Japan) in a shielded room. The H-reflex and M-wave were elicited according to the standard clinical protocol ${ }^{15-17)}$. Briefly, a percutaneous electric stimulus was randomly applied to the tibial nerve at the popliteal fossa, for $0.5 \mathrm{~ms}$ at a frequency of $1 \mathrm{~Hz}$ or lower ${ }^{9,15,16)}$. Beginning with a low-intensity stimulus and gradually increasing its intensity generates an H-reflex tracing on the electromyogram (EMG). Continuing to increase the stimulus intensity achieves the motor fiber depolarization threshold and the appearance of an M-wave together with an H-reflex. Continuing to increase the stimulus intensity eventually results in an H-reflex reaching its maximum and then disappearing from the EMG tracing, whereas an $\mathrm{M}$-wave achieves its maximum and remains stable. The $\mathrm{H} / \mathrm{M}$ ratio was calculated by comparing the intensity at the maximum H-reflex and that at the maximum M-wave (Fig. 2).

The H-reflex is susceptible to both central and peripheral nervous system activities as well as external factors such as sleeping ${ }^{16)}$, eye closure $^{9)}$, vibratory stimulation ${ }^{16)}$, muscle contraction ${ }^{5,9,16)}$, joint position and angle ${ }^{9)}$, and head position ${ }^{9)}$. To avoid these influences, we instructed the subjects to rest in a prone position with their feet (specifically the ankles) off the bed to prevent 


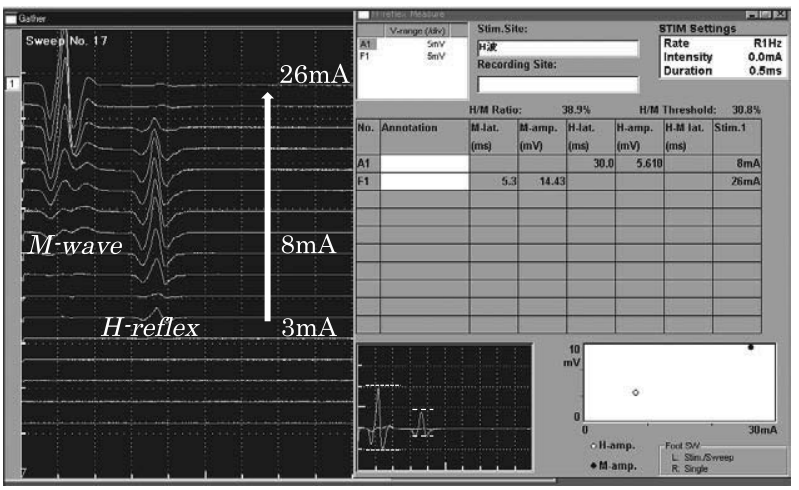

Fig. 2. H-reflex and M-wave recording The H-reflex and M-wave were obtained as stimulation intensity was gradually increased from $3 \mathrm{~mA}$ to $26 \mathrm{~mA}$. This recording shows that the maximum $\mathrm{H}$-reflex was $5.61 \mathrm{mV}$ and the maximum $\mathrm{M}$-wave was $14.43 \mathrm{mV}$, and the $\mathrm{H} / \mathrm{M}$ ratio was thus calculated to be $38.9 \%$

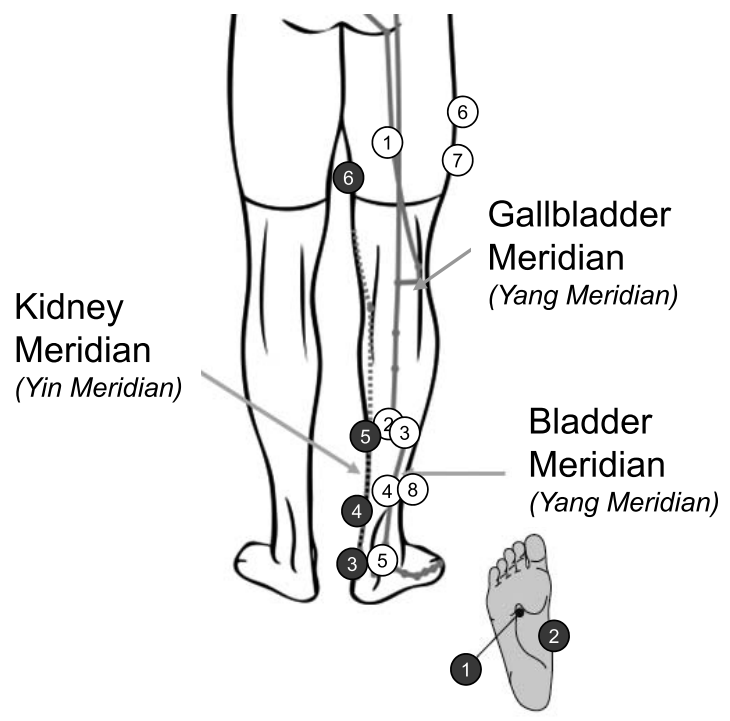

Fig. 3. Stimulation sites (14 acupuncture points) Somareson II was applied at Yang Meridians: (1) $B L 37$ (尉門; Ynmen), (2) BL 57 (承山; Chengshan), (3) BL 58 (飛揚; Feiyang), (4) BL 59 (䟰陽; Fuyang), (5) BL 60 (崖崙; Kunlun), 6 GB 31 (風市; Fengshi), (7) GB 33 (足陽関; Xiyangguan), and 8 GB 38 (陽輔; Yangfu) Somacept II was applied at Yin Meridian: 1 KI 1 (涌 泉; Yong Quan), 2 KI 2 (然谷; Rangu), 3 KI 4 (大 鐘; Da zhong), 4 KI 7 (復溜; Fulieu), 5 KI 9 (築賓; Zhubin), 6 LR 9 (陰包; Yinbao)

contraction of the triceps surae muscle during testing. Subjects were also instructed to maintain the same body position during measurement, and were engaged in conversation to keep them awake during the procedures.

3) Stimulation sites (acupuncture points)

For paretic subjects, acupuncture stimulation was performed on the paretic limbs (right and left in 4 subjects each). For healthy subjects, the limbs to undergo stimulation were determined by asking them which side felt most tense during the voluntary movement of dorsal flexion of the ankle joint (the limb perceived to have greater tension was chosen). If the subject perceived no difference, the limb more resistant to passive movement (dorsal flexion of the ankle joint) was chosen (right in 12 subjects and left in 5 subjects).

Stimulation sites (acupuncture points) were selected from frequently employed sites for acupuncture treatment of paretic patients using the Meridian-Test (M-Test) ${ }^{18)}$. The following 14 lower limb acupuncture points were selected: Somareson II was applied at Kunlun (宸崙; BL 60), Chengshan (承山; BL 57), Feiyang (飛揚; BL 58), Fuyang (䟷陽；BL 59), Yinmen (殷門; $B L$ 37), Fengshi (風市; $G B$ 31), Xiyangguan (足陽関; $G B$ 33), and Yangfu (陽輔; $G B$ 38); Somacept II was applied at Yong Quan (涌永; KI 1), Rangu (然谷; KI 2), Da zhong (大鐘; KI 4), Fulieu (復溜; KI 7), Zhubin (築瞽; KI 9), and Yinbao (陰包; LR 9) (Fig. 3). These acupuncture points are located mainly in the Achilles tendon, triceps surae muscle, and surrounding 
area. The M-Test is both a diagnostic and a treatment method that identifies abnormal meridians based on symptoms accompanying body movements. In this study, kidney meridian (KI) and bladder meridian (BL) were selected because they relate to dorsal flexion of the ankle joint, while liver meridian (LR) and gallbladder meridian (GB) were selected because they relate to ankle inversion and eversion.

4) Acupuncture types used

Cutaneous stimulation was performed using two contact acupuncture types: Somareson II (SR II) and Somacept II (SC II), which are made of elastomer resin and plastic resin, respectively (TOYO RESIN Corp., Shizuoka, Japan) (Fig. 4). The SR II is softer than the SC II, but both products are used for continuous cutaneous stimulation without pain (there are no needles to insert into the skin). The contact acupuncture device comprises brush-like microcones with a height of $0.3 \mathrm{~mm}$ (SR II) or $0.15 \mathrm{~mm}$ (SC II) attached a disc-shaped base with a thickness of $0.3 \mathrm{~mm}$ and a diameter of $11 \mathrm{~mm}$. The sham acupuncture device was made of the same materials and had the same shape except for the disc-shaped base, which had a flat surface without microcones. The sham acupuncture device was developed by TOYO RESIN for research purposes. There was no difference in the appearance between the true and sham acupuncture devices. Contact acupuncture is suitable for studies such as this because it facilitates maintenance of a certain level of dosing and it does not require specific skills; however, there is no established standard procedure for the two contact acupuncture types employed herein. We used SR II for

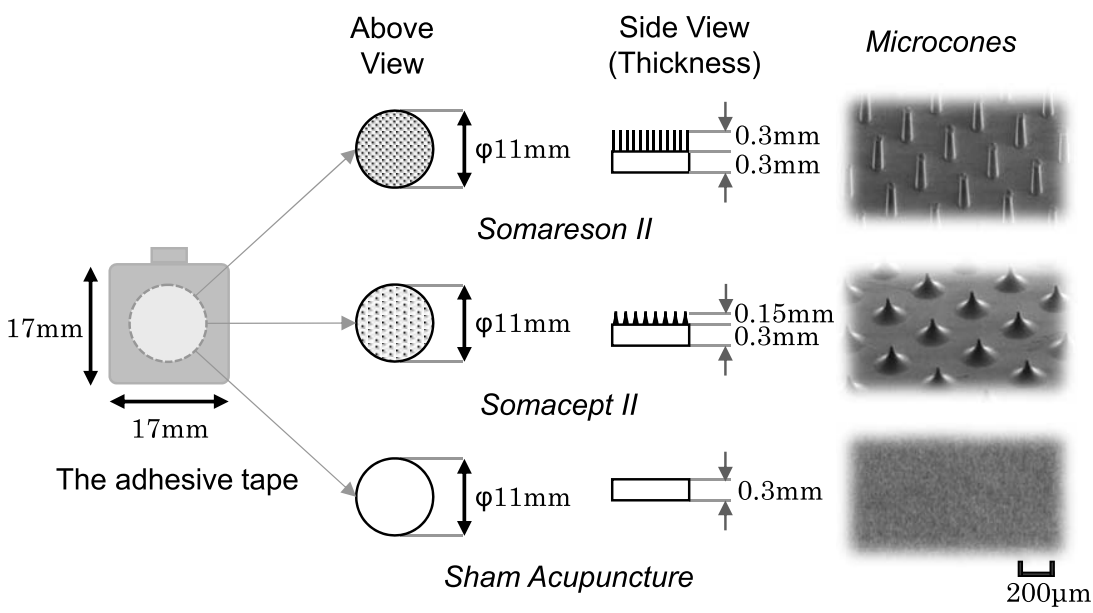

Fig. 4. Structure of contact acupuncture needles and enlarged view of microcones The adhesive tape used for all acupuncture needles was of the same material and shape, with a contact disc at the center. Somareson II (upper part) : 417 microcones with a height of $0.3 \mathrm{~mm}$ were arranged on the transparent discshaped base made of elastomer resin with a diameter of $11 \mathrm{~mm}$ and a thickness of $0.3 \mathrm{~mm}$. Somacept II (middle section) : 376 microcones with a height of $0.15 \mathrm{~mm}$ were arranged on the colorless and transparent disc-shaped base made of plastic resin with a diameter of $11 \mathrm{~mm}$ and a thickness of $0.3 \mathrm{~mm}$. Sham acupuncture (lower section): The device was developed by TOYO RESIN Corp. for research purposes. It had same composition, shape, and the disc-shaped base at the center with a diameter of $11 \mathrm{~mm}$ and a thickness of $0.3 \mathrm{~mm}$ as the other two types except for having a flat surface without microcones. 
Yang meridians (陽経), which include the Gallbladder and Bladder Meridians, and SC II for Yin meridians (陰経), which include the Kidney Meridian, based on our clinical experience (Fig. 3). In addition, cutaneous stimulation was performed by same acupuncturist who had 10 years of clinical experience.

5) Randomized, double-blind, crossover design and blinding of the study

A person not involved with the study measurements performed the randomization using the random function in Microsoft Excel (Microsoft Japan Co., Ltd., Tokyo, Japan). Subjects were randomly allocated to one of the two groups using odd and even numbers (group A, 4 paretic subjects and 8 healthy subjects; group B, 4 paretic subjects and 9 healthy subjects). To maintain the blinding of this study, contact and sham acupunctures with identification numbers were kept in the same box by a person who was not involved in the measurement procedures. Examiners were blinded to the allocations until all measurements had been completed.

\section{Statistical analysis}

Statistical analysis was performed using SPSS statistics ver. 23 (IBM, Tokyo, Japan). The significance level was set at $5 \%$. The Spearman rank-correlation coefficient was used to evaluate relationships of the pre-stimulation $\mathrm{H} / \mathrm{M}$ ratios with age and gender. The pre-stimulation $\mathrm{H} / \mathrm{M}$ ratio was normalized for analysis, and ratio changes after stimulation were compared between the contact and sham acupunctures using one-way analysis of variance and multiple comparisons. Other comparisons between two groups were carried out using the Mann Whitney-U test.

\section{Results}

Three patients were excluded from the final analysis: one paretic subject (group B) was unable to maintain a prone position, one healthy subject (group B) was unable to complete the measurements because of pain with electrical stimulation, and one healthy subject (group A) showed a $1.5 \mathrm{~ms}$ or more difference in the latency of the H-reflex between the right and left limbs, suggesting S1 nerve root impairment ${ }^{15)}$ (Fig. 1). No patient reported adverse events during either contact or sham acupuncture stimuli periods.

To confirm the validity of the randomization process, age, gender, lower limb Brunnstrom stage, MAS, and the time since onset (the latter three applied only to paretic subjects) were compared between groups A and B. No significant differences were observed, confirming the success of randomization.

\section{Comparison of pre-stimulation H/M ratios between paretic and healthy subjects}

The pre-stimulation $\mathrm{H} / \mathrm{M}$ ratio was compared between paretic and healthy subjects (Table 2). The pre-stimulation $\mathrm{H} / \mathrm{M}$ ratio of the paretic limb was significantly higher than that of the unaffected limb $(P<0.05)$ and that of the stimulated limb in healthy subjects $(P<0.05)$. The H/M ratio of the unaffected limb also tended to be lower in the paretic than in the healthy subjects, although the difference was not statistically significant. There was no significant difference between the $\mathrm{H} / \mathrm{M}$ ratios for stimulated and unstimulated limbs in the healthy subjects. 
Table 2. Pre-stimulation $\mathrm{H} / \mathrm{M}$ ratio

\begin{tabular}{lccc}
\hline & \multicolumn{3}{c}{ Maximum H/M ratio (\%) of pre-stimulations } \\
\cline { 2 - 4 } & Patients $(\mathrm{n} 7)$ & Volunteers $(\mathrm{n} 15)$ & P-value \\
\hline Affected/Stimulated limb & $46.49 \pm 9.42$ & $33.34 \pm 11.43$ & $0.017^{\star}$ \\
Unaffected/Unstimulated limb & $27.67 \pm 10.75$ & $36.14 \pm 16.04$ & 0.332 \\
P-value & $0.011^{\star}$ & 0.599 & \\
\hline
\end{tabular}

Mean \pm Standard Deviation, ${ }^{\star}: p<0.05, \mathrm{n}:$ number
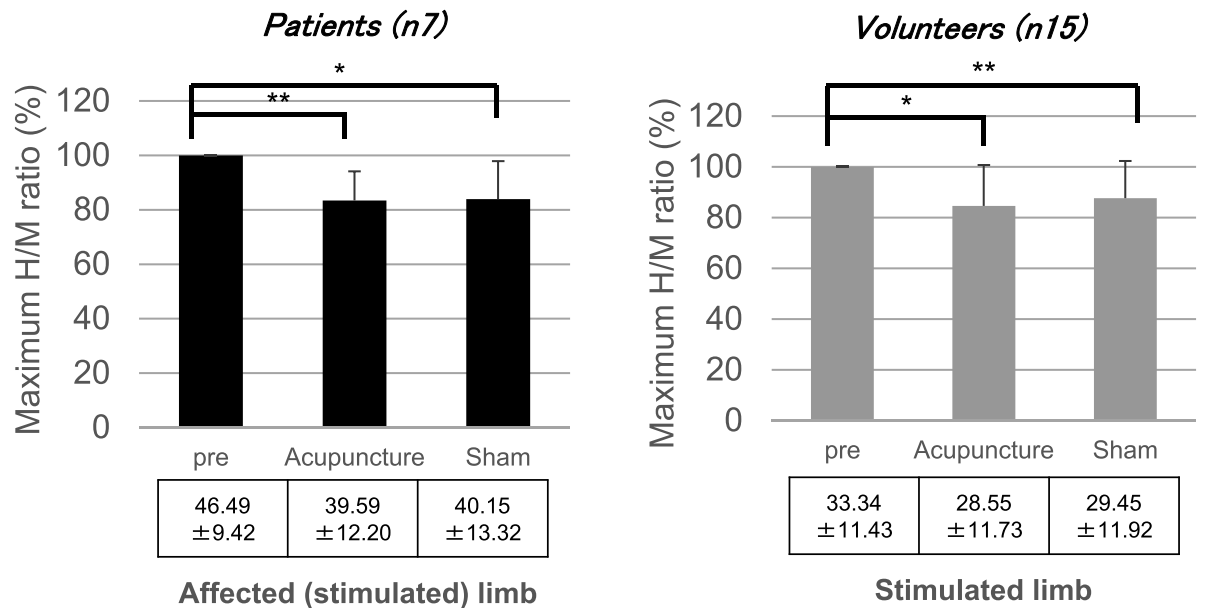

Fig. 5. Changes in $\mathrm{H} / \mathrm{M}$ ratios of the stimulated limbs

The pre-stimulation data were normalized to allow for comparison with the poststimulation data. Paretic subjects showed a significant $\mathrm{H} / \mathrm{M}$ ratio decrease after contact and sham acupuncture (shown on the left). Healthy subjects also showed a significant $\mathrm{H} / \mathrm{M}$ ratio decrease after contact and sham acupuncture (shown on the right). Mean value \pm standard deviation, ${ }^{*}: p<0.05,{ }^{* *}: p<0.01, \mathrm{n}:$ number, pre: pre stimulation, Acupuncture : contact acupuncture, Sham : sham acupuncture.

Examination of $H / M$ ratio relationships with age and gender

The pre-stimulation $\mathrm{H} / \mathrm{M}$ ratio showed no significant correlation with either age (rs $=0.066, P$ $=0.772$ ) or gender ( $\mathrm{rs}=0.007, P=0.974)$.

\section{Changes in $H / M$ ratios after contact and sham acupunctures}

Fig. 5 shows the $\mathrm{H} / \mathrm{M}$ ratio changes in stimulated limbs. Both paretic and healthy subjects showed significant $\mathrm{H} / \mathrm{M}$ ratio decreases after contact acupuncture $(P<0.05)$ and sham acupuncture $(P<0.05)$. In addition, there were no significant $\mathrm{H} / \mathrm{M}$ ratio differences between contact and sham acupunctures in either paretic or healthy subjects.

Fig. 6 shows the comparisons between groups A and B. Paretic patients showed no significant differences between the two groups in $\mathrm{H} / \mathrm{M}$ ratio (1) (pre-stimulation), H/M ratio (2) (group A, contact acupuncture; group $\mathrm{B}$, sham acupuncture), or $\mathrm{H} / \mathrm{M}$ ratio (3) (group A, sham acupuncture; group B, contact acupuncture), nor was there any effect of the order of stimulation. In 

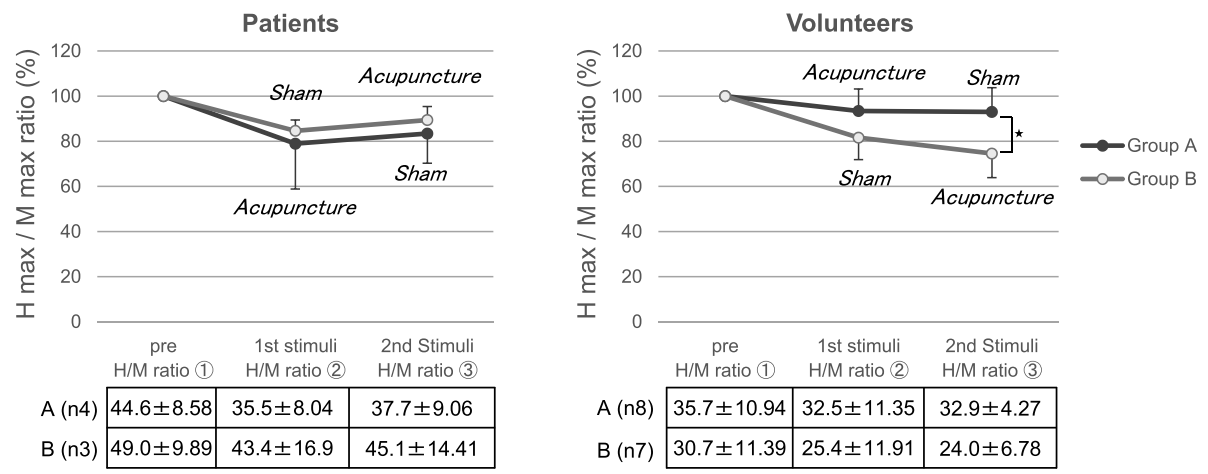

Fig. 6. Comparison of $\mathrm{H} / \mathrm{M}$ ratios between groups $\mathrm{A}$ and $\mathrm{B}$

The pre-stimulation data were normalized to allow for comparison with the post-stimulation data. The $\mathrm{H} / \mathrm{M}$ ratio changes after stimulation were compared between groups $\mathrm{A}$ and $\mathrm{B}$. The data of paretic and healthy subjects are shown on the left and right, respectively. Numerical data are shown in the tables at the bottom. Mean \pm standard deviation, ${ }^{\star}: p<0.05, \mathrm{n}:$ number, pre : pre stimulation, Acupuncture: contact acupuncture, Sham : sham acupuncture, A : Group A, B : Group B.

healthy subjects, H/M ratio (3) was significantly lower in group B (with contact acupuncture) than in group $\mathrm{A}$ (with sham acupuncture) $(P<0.05)$.

\section{Changes in the H/M ratios of the unstimulated limbs (contralateral side)}

Comparison of $\mathrm{H} / \mathrm{M}$ ratio changes of the unstimulated limbs showed no significant difference in the comparison of the first measurement $\mathrm{H} / \mathrm{M}$ (4) and second measurement $\mathrm{H} / \mathrm{M}$ (5) in paretic subjects (Fig. 7). In healthy subjects, the $\mathrm{H} / \mathrm{M}$ ratio of unstimulated limbs in the second measurement $(\mathrm{H} / \mathrm{M}$ ratio (5)) was significantly lower than that in the first measurement $(\mathrm{H} / \mathrm{M}$ ratio (4)) $(P<0.05)$.

\section{Discussion}

We conducted a randomized, double-blind, crossover study of the neurophysiological effects of cutaneous stimulation on muscle tone by measuring the $\mathrm{H} / \mathrm{M}$ ratios of soleus muscle following contact and sham acupunctures in paretic and healthy subjects. We found that paretic patients had a decreased $\mathrm{H} / \mathrm{M}$ ratio in the affected limb after cutaneous stimulations, even though there were no significant differences in the effects between contact and sham acupunctures. In addition, the order of stimulation did not affect the results. These findings suggest that gentle cutaneous stimulation decreases the excitation of motor neurons in the anterior horn of the spinal cord, and that these effects are unrelated to the presence of microcones. Increased muscle tone in spastic paresis results from increased spinal motor neuron excitation that is not easily suppressed by rest alone ${ }^{19)}$. Our results support this notion, as the $\mathrm{H} / \mathrm{M}$ ratio measured herein was unchanged in the unstimulated limb (unaffected side) of paretic subjects. Therefore, we regard rest alone as being insufficient to treat this patient group. Together, these findings suggest that cutaneous stimulation applied to paretic limbs would be beneficial in clinical practice. 


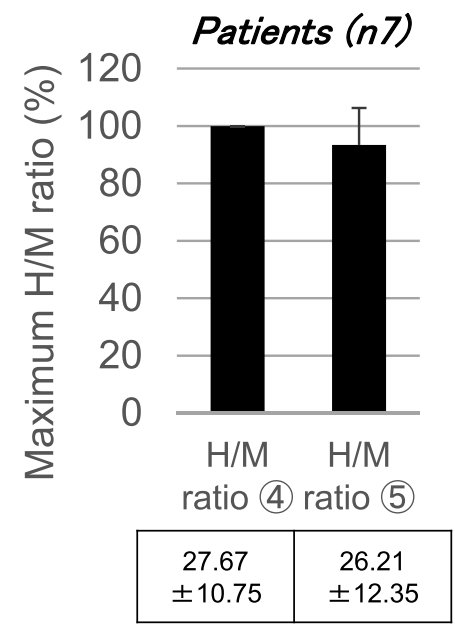

Unaffected

(Unstimulated) limb

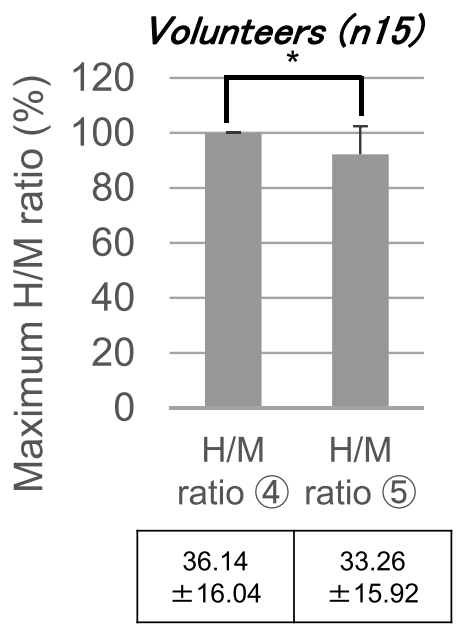

Unstimulated limb

Fig. 7. Changes in the $\mathrm{H} / \mathrm{M}$ ratios of unstimulated limbs Measurements of the $\mathrm{H} / \mathrm{M}$ ratios of the unstimulated limbs were performed twice at an interval of at least 45 minutes. Paretic subjects showed no significant $\mathrm{H} / \mathrm{M}$ ratio change (shown on the left), while healthy subjects showed a significant $\mathrm{H} / \mathrm{M}$ ratio decrease ( $p$ $<0.05$ ) (shown on the right) Mean value \pm standard deviation, ${ }^{*}: p<$ $0.05, \mathrm{n}:$ number.

In healthy subjects, the $\mathrm{H} / \mathrm{M}$ ratio was significantly decreased in both the stimulated and unstimulated limbs after cutaneous stimulations with contact and sham acupunctures. Given that healthy subjects do not have upper motor neuron dysfunction, we propose the following underlying mechanism for this effect: a decrease in excitation of motor neurons on the stimulated side leads to descending inhibition (transcallosal inhibition) on the contralateral side via the upper central nervous system, with a possible interaction between the two. Further, it is reported that prolonged rest with the eyes closed leads to a decrease in the amplitude of the H-reflex ${ }^{9}$.

Unlike in the paretic patients, healthy subjects who received contact acupuncture for the second measurement ( $\mathrm{H} / \mathrm{M}$ ratio (3) ) showed a significant $\mathrm{H} / \mathrm{M}$ ratio decrease compared to those who received the sham stimulation second. Paretic subjects would be expected to have a lower threshold of excitement in the cortex on the affected side ${ }^{19)}$, and this may explain the lack of a difference between contact and sham acupuncture, whereas in healthy subjects, the decrease in the second measurement may be related to adaptation of the relevant mechanoreceptors. We set the adaptation time or washout time at 15 minutes as based on previous studies using contact acupuncture $^{23,24)}$, but there is no consensus regarding this point, and a longer time might be needed to clarify the effects.

Spasticity is a motor disorder characterized by a velocity-dependent increase in the tonic stretch reflexes ('muscle tone') with exaggerated tendon jerks, resulting from hyperexcitability of the stretch reflex ${ }^{20)}$. Patients with chronic paresis tend to experience immobility and disuse of the limb, leading to changes in elasticity of the muscle, tendon, joint, and soft tissue ${ }^{3,21)}$. Overall 
assessment of spasticity is difficult, thus herein we focused on muscle tone only and used H/M ratios for the quantitative evaluation of hyperexcitability.

The H-reflex is an estimate of $\alpha$-motor neuron excitability when presynaptic inhibition and intrinsic excitability remain constant ${ }^{9)}$. The M-wave is a compound muscle action potential evoked by excitation of $\alpha$-motor neurons in response to electrical stimulation. The $\mathrm{H} / \mathrm{M}$ ratio has been used for evaluating muscle tone ${ }^{5-9)}$ as an index of how much of the excited anterior horn motor neurons dominate the muscle tone in response to electrical stimulation ${ }^{9,15)}$. Volunteers with spasticity or increased excitability of spinal neurons have higher $\mathrm{H} / \mathrm{M}$ ratios ${ }^{15-17)}$; however, as there is broad variation in data among this population ${ }^{16,17)}$, we performed a relative evaluation in this study.

In recent years, studies have demonstrated the effects of pleasant touch on single afferent fiber activities in cutaneous nerves ${ }^{22-25)}$. Pleasant touch activates mechanoreceptors in the skin ${ }^{23)}$, which changes autonomic function, and suppresses stress ${ }^{23-25)}$. The afferent fibers involved in regulating muscle tone consist of not only Ib and II fibers of the homonymous muscle, but also fibers in the cutaneous nerves ${ }^{21)}$. Afferent fibers in the cutaneous nerves can reportedly suppress spinal reflex activity through sensory input (suppression of motor neuron excitation) ${ }^{26)}$. In addition, although presynaptic inhibition via intermediate neurons from $\mathrm{Ia}$ and $\mathrm{Ib}$ fibers in the heteronymous muscles is decreased during spasticity ${ }^{27)}$, specific cutaneous sensory input is reported to activate inhibitory intermediate neurons and increase reciprocal inhibition (increased inhibitory input ${ }^{28)}$. This study has not provided conclusive evidence about the neurophysiological mechanisms underlying our results; however, we speculate that cutaneous afferent nerve activity induced by gentle cutaneous stimulation activated inhibitory intermediate neurons, leading to the suppressed excitation of motor neurons (Fig. ${ }^{30)}$ ). This hypothesis is based on the assumption that inputs from the cutaneous nerve to the primary afferent fibers are integrated with descending impulses from the central nervous system before being sent to motor neurons ${ }^{29)}$.

The sham acupuncture also decreased H/M ratios in this study, and we observed residual indentations of the skin after removing both the contact and sham acupuncture devices. Mechanoreceptors, located in the epidermis and dermis, are responsive to slight indentation $(0.1-1.5 \mathrm{~mm})$ of the $\operatorname{skin}^{31}$. Given that the difference in thickness between contact acupuncture (SR II, $0.6 \mathrm{~mm}$; SC II, $0.45 \mathrm{~mm}$ ) and sham acupuncture $(0.3 \mathrm{~mm}$ ) was only $0.3 \mathrm{~mm}$ or $0.15 \mathrm{~mm}$ (Fig. 4), it is possible that both procedures excited the dermal mechanoreceptors. Hotta et $a l^{23)}$ examined the effects of contact stimulation with both contact and sham acupunctures on the skin of anesthetized rats and reported that sham acupunctures did not inhibit the C-reflex. Based on their findings, we had expected the contact acupuncture to be superior to the sham acupuncture ; however, this was not the case herein. Another study found that cutaneous stimulation with a roller (made of the same material as the sham acupuncture device used in the present study) was effective for treating overactive bladder-related nocturia in elderly women ${ }^{25)}$. Further investigations of stimulation modalities are needed, including the degree of skin compression and the stimulation materials.

There is no consensus as to the optimal acupuncture points for treating spasticity ${ }^{10)}$. For 


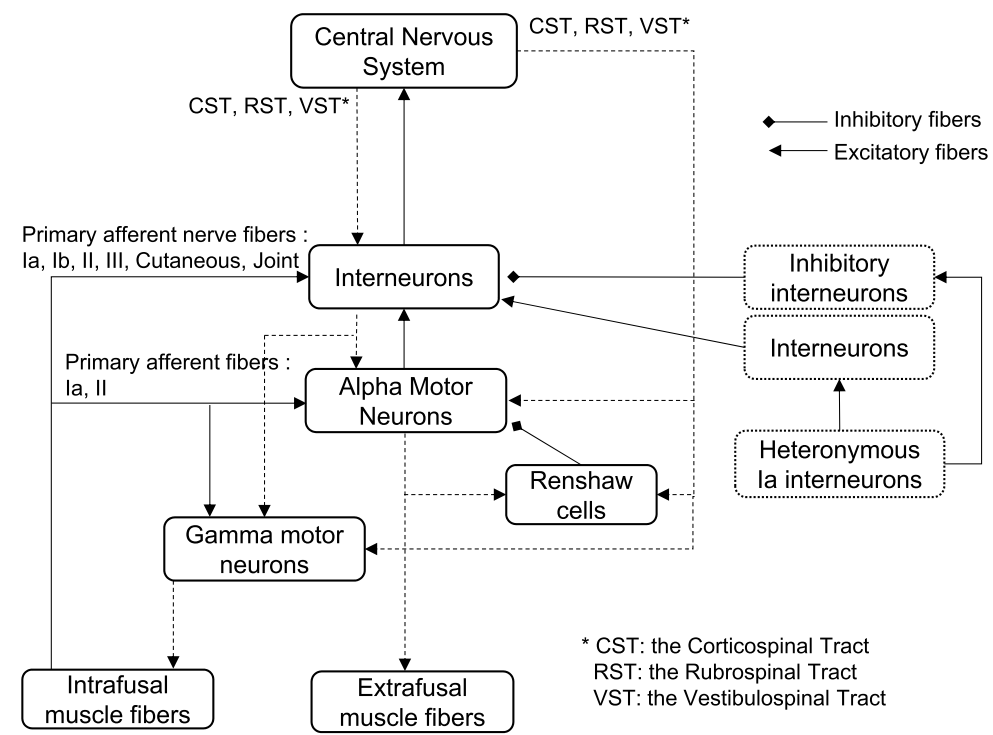

Fig. 8. Nervous system influence on the spinal reflex (cited from [30] with modification)

The solid line indicates afferent fibers. The dashed line indicates efferent fibers. Arrows represent excitatory actions. Lozenges represent inhibitory actions. The fibers of heteronymous muscles are enclosed by dashed lines.

this study, we selected acupuncture points that are frequently used in treatments based on the M-Test. Takahashi et al $^{32)}$ reported that cutaneous stimulation of the Achilles tendon attachment site using “shu-mo shin (集毛鍼)" (a different type of contact acupuncture) decreased the H/ $\mathrm{M}$ ratio, although the rationale for selecting these acupuncture points was not addressed in their study. In addition, the H/M ratio decrease in the study by Takahashi et al was observed only during stimulation with shu-mo shin, suggesting that the attachment-type contact acupuncture might be more effective overall compared to shu-mo shin.

Previous studies have also reported no beneficial effect of acupuncture on reducing spasticity in post-stroke patients ${ }^{10,11)}$, although other findings suggest that acupuncture stimulation could have an adjuvant effect on spasticity reduction by modulating $\alpha$-motor neuron activity ${ }^{10)}$. Our results suggest that gentle cutaneous stimulation under some conditions might reduce the excitability of these neurons at rest, and support the adjuvant effect of rehabilitation exercise for patients with spastic muscle hypertonia. Further trials with larger numbers of subjects are required to reach a more definitive conclusion about the benefits or otherwise of contact acupuncture for spasticity.

\section{Limitations}

The H-reflex is susceptible to changes in room temperature ${ }^{5,32)}$ and medication ${ }^{16)}$. Herein we did not obtain information on medications being taken by our subjects, and the room temperature was not measured although it was set at $24-26^{\circ} \mathrm{C}$ during the study period. In addition, the influence of eye closure on the results was unavoidable. The present findings are thus only 
applicable to resting conditions. The effects on muscle tone during voluntary movement await future study.

\section{Acknowledgements}

This study was supported by the public interest-incorporated Foundation for Training and Licensure Examination in Anma-Massage-Acupuncture, and Moxibustion (2014).

We deeply thank Professor, M.D. Y. Mukaino, Department of Sports Science and Health and Exercise Science, Faculty of Sports and Health Science, Fukuoka University, for encouragement in performing this study.

This study was approved by the Ethics Committee of Showa University School of Medicine (approval number: 2013062) and enrolled in UMIN (UMIN000016171).

\section{Conflict of interest disclosure}

The authors declare that there are no conflicts of interest.

\section{References}

1) Dietz V, Sinkjaer T. Spastic movement disorder: impaired reflex function and altered muscle mechanics. Lancet Neurol. 2007;6:725-733.

2) Smania N, Picelli A, Munari D, et al. Rehabilitation procedures in the management of spasticity. Eur J Phys Rehabil Med. 2010;46:423-438.

3) Takeuchi N. Treatment approach for spasm in patients with chronic-phase stroke. Jpn J Phys Ther. 2007;41:277-285. (in Japanese).

4) Bakheit AM, Maynard VA, Curnow J, et al. The relation between Ashworth scale scores and the excitability of the alpha motor neurones in patients with post-stroke muscle spasticity. J Neurol Neurosurg Psychiatry. 2003;74:646-648.

5) Nakamura K, Kodama T, Mukaino Y, et al. EMG analysis of the stretching effect on the soleus muscle. Jpn $J$ Health Promot Phys Ther. 2014;4:125-128. (in Japanese).

6) Bakheit AM, Maynard V, Shaw S. The effects of isotonic and isokinetic muscle stretch on the excitability of the spinal alpha motor neurones in patients with muscle spasticity. Eur J Neurol. 2005;12:719-724.

7) Ota T. Clinical and electrophysiological effects of transcutaneous electrical stimulation in hemiplegic patients. Jpn J Rehabil Med. 2001;38:109-118. (in Japanese).

8) Funase K, Higashi T, Sakakibara A, et al. Neural mechanism underlying the H-reflex inhibition during static muscle stretching. Abv Exer Sport Physiol. 2003;9:119-127.

9) Palmieri RM, Ingersoll CD, Hoffman MA. The hoffmann reflex: methodologic considerations and applications for use in sports medicine and athletic training research. $J$ Athl Train. 2004;39:268-277.

10) Park SW, Yi SH, Lee JA, et al. Acupuncture for the treatment of spasticity after stroke: a meta-analysis of randomized controlled trials. J Altern Complement Med. 2014;20:672-682.

11) Park J, Hopwood V, White AR, et al. Effectiveness of acupuncture for stroke: a systematic review. J Neurol. 2001;248:558-563.

12) Bohannon RW, Smith MB. Interrater reliability of a modified Ashworth scale of muscle spasticity. Phys Ther. 1987;67:206-207.

13) Brunnstrom S. Motor testing procedures in hemiplegia : based on sequential recovery stages. Phys Ther. 1966;46:357-375.

14) Ishida A. Post stroke evaluation scale. Brain Circ. 1999;4:151-159. (in Japanese).

15) Kimura J, Kohara N. The principle of the examination of nerve conduction and the practice. In Electromyography nerve conduction studies. 2nd ed. Tokyo: Igaku Shoin; 2010. pp97-101. (in Japanese). 
16) Fujiwara T. The evoked electromyograms. In A manual of electromyography and evoked potentials. 2nd ed. Kyoto: Kinpodo; 1992. pp65-71. (in Japanese).

17) Takahashi N. Assessment of spasm and reciprocal inhibition. J clin rehabil. 2013;22:294-299. (in Japanese).

18) Mukaino Y, Matsumoto M, Yamashita N. The theoretical background of the M-Test. In M-Test. Tokyo: Igaku Shoin; 2012. pp7-22. (in Japanese).

19) Suzuki T, Tani M, Nabeta R, et al. Spasticity and associated reaction in the hemipalysis patient caused by cerebrovascular diseases. J Kansai Phys Ther. 2001;1:35-41. (in Japanese).

20) Lance JW. Symposium synopsis. In Feldman RG, Young RR, Koella WP, eds. Spasticity: disordered motor control. Chicago: Year Book Medical Publisher; 1980. pp485-494.

21) Suzuki T. Pathophysiology and electrophysiological assessment of spasm. Med Rehabil. 2015;(180): 23-28. (in Japanese).

22) Loken LS, Wessberg J, Morrison I, et al. Coding of pleasant touch by unmyelinated afferents in humans. Nat Neurosci. 2009;12:547-548.

23) Hotta H, Schmidt RF, Uchida S, et al. Gentle mechanical skin stimulation inhibits the somatocardiac sympathetic C-reflex elicited by excitation of unmyelinated C-afferent fibers. Eur J Pain. 2010;14:806-813.

24) Watanabe N, Miyazaki S, Mukaino Y, et al. Effect of gentle cutaneous stimulation on heat-induced autonomic response and subjective pain intensity in healthy humans. J Physiol Sci. 2012;62:343-350.

25) Iimura $\mathrm{K}$, Watanabe $\mathrm{N}$, Masunaga $\mathrm{K}$, et al. Effects of a gentle, self-administered stimulation of perineal skin for nocturia in elderly women: a randomized, placebo-controlled, double-blind crossover trial. PLoS One (Internet). 2016;11:e0151726. (accessed 2016 Mar 22) Available form : http://journals.plos.org/plosone/article?id=10.1371\%2Fjournal. pone.0151726

26) Seki M. Biomechanical properties during passive ankle movement in spastic hemiplegic patients. Jpn J Rehabil Med. 2001;38:259-267. (in Japanese).

27) Cannon BW, Beaton LE, Ranson SW. Nature of paresis following lateral cortico-spinal section in monkeys. $J$ Neurophysiol. 1943;6:425-430.

28) Perez MA, Field-Fote EC, Floeter MK. Patterned sensory stimulation induces plasticity in reciprocal Ia inhibition in humans. J Neurosci. 2003;23:2014-2018.

29) Suzuki T. Spinal neural function for motor control. J Kansai Phys Ther. 2005;5:1-9. (in Japanese).

30) Suzuki T, Saitoh E. Reflex. Gen Rehabil. 2000;28:515-520. (in Japanese).

31) Johnson KO. The roles and functions of cutaneous mechanoreceptors. Curr Opin Neurobiol. 2001;11:455-461.

32) Takahashi M, Tani M, Suzuki T. Effect of epidermal penetration by needle stimulation to make an insertion in the achilles tendon of the soleus H-reflex: A two-minute examination. Kampo Med. 2016;67:22-27. (in Japanese).

[Received September 26, 2016 : Accepted November 16, 2016] 